\title{
Oncology
}

\section{Cetuximab in Pancreatic Cancer Therapy: A Systematic Review and Meta-Analysis}

\author{
Tobias Forster $^{a-c}$ Felix J. Huettner ${ }^{a, b} \quad$ Christoph Springfeld $^{d} \quad$ Matthias Loehr $^{\mathrm{e}}$ \\ Eva Kalkum $^{b}$ Matthes Hackbusch ${ }^{f}$ Thilo Hackert ${ }^{a}$ Markus K. Diener ${ }^{a}$ b \\ Pascal Probst ${ }^{\mathrm{a}, \mathrm{b}}$ \\ ${ }^{a}$ Department of General, Visceral and Transplantation Surgery, University of Heidelberg, Heidelberg, Germany; \\ ${ }^{\mathrm{b}}$ The Study Center of the German Surgical Society (SDGC), University of Heidelberg, Heidelberg, Germany; \\ 'Department of Radiation Oncology, University of Heidelberg, Heidelberg, Germany; ${ }^{\mathrm{d}}$ National Center of Tumor \\ Disease, University of Heidelberg, Heidelberg, Germany; ${ }^{~}$ Karolinska Institutet, CLINTEC, Center for Digestive \\ Diseases, Karolinska University Hospital, Stockholm, Sweden; Institute of Medical Biometry and Informatics, \\ University of Heidelberg, Heidelberg, Germany
}

\section{Keywords}

Cetuximab · Pancreatic cancer - Palliative cancer therapy · Targeted therapy · Survival

\begin{abstract}
Introduction: The present study evaluated the potential benefit of adding cetuximab to neoadjuvant, adjuvant, or palliative standard therapy for pancreatic cancer. Methods: A systematic literature search was performed in MEDLINE, Web of Science, and Cochrane Central Register of Controlled Trials (CENTRAL). Only randomised controlled trials (RCTs) investigating the effect of adding cetuximab to standard chemotherapy in pancreatic cancer were included. Evaluated outcomes were overall survival, progression-free survival, objective response, and toxicity. For overall survival and progression-free survival, hazard ratios (HR) with 95\% confidence intervals $(\mathrm{Cl})$ were chosen as effect measure. For objective response, odds ratios (OR) with $95 \% \mathrm{Cl}$ were used. Analysis was based on a random effects model. Results: After screening 568 publications, a total of 4 RCTs with 924 patients were included. In all trials, patients were adequately randomised with balanced intervention and control groups.
\end{abstract}

There was no significant difference in overall survival (HR 1.04; 95\% Cl: 0.90-1.19; $p=0.60$ ), progression-free survival (HR 1.06; 95\% Cl: 0.93-1.22; $p=0.36$ ), or objective response (OR 0.99; 95\% Cl: $0.66-1.49 ; p=0.96$ ) when adding cetuximab to a standard therapy. Toxicity was the same or higher in each of the included trials. According to GRADE, the certainty of the evidence is high. Therefore, adding cetuximab to pancreatic cancer therapy has no clinically relevant benefit. Conclusion: In the presence of no survival benefit, increased toxicity, and higher costs, a decreased cost-benefit ratio compared to the standard care must be suggested. Conducting further RCTs in unselected pancreatic cancer populations is unlikely to change this conclusion.

(c) 2019 S. Karger AG, Basel

\section{Introduction}

Pancreatic ductal adenocarcinoma is one of the most aggressive malignancies [1] and is typically diagnosed in an advanced state $[2,3]$, as it is characterised by early locoregional spread and distant metastasis. Gemcitabine used to be the standard first-line therapy for advanced

\section{KARGER}

(C) 2019 S. Karger AG, Basel

E-Mail karger@karger.com

www.karger.com/ocl
PD Dr. med. Pascal Probst

Department of General, Visceral and Transplantation Surgery

University of Heidelberg, Im Neuenheimer Feld 110

DE-69120 Heidelberg (Germany)

E-Mail pascal.probst@med.uni-heidelberg.de 
pancreatic cancer for many years [3]. However, 1-year survival after gemcitabine therapy was reported at only 18 $29 \%[4,5]$. Thus, alternate treatments for this disease are urgently needed. Novel chemotherapy combinations like FOLFIRINOX [6] or gemcitabine plus nab-paclitaxel have significantly improved overall survival for patients with metastatic disease. Unfortunately, except for erlotinib, targeted agents have proved unsuccessful in clinical pancreatic cancer trials to date [7]. Erlotinib with gemcitabine was superior to gemcitabine in a randomised phase III study, but the difference in overall survival was so small that the clinical relevance of this benefit is controversial [8]. Cetuximab, another targeted agent, has been tested in various clinical studies for pancreatic cancer [9-13]. Cetuximab is an immunoglobulin G1 monoclonal antibody that binds the epidermal growth factor receptor (EGFR) with high affinity, which competitively blocks ligand binding, inhibits tyrosine kinases activation, and results in receptor downregulation [14]. In $22-60 \%$ of human pancreatic carcinomas, EGFR is overexpressed $[15,16]$. While some preclinical research shows positive results $[17,18]$, the effect of cetuximab in treating pancreatic cancer remains controversial [13]. Older systematic reviews evaluating the effect of cetuximab in pancreatic cancer also show inconsistent results $[19,20]$. Further recent RCTs, which have not been considered in previous reviews, are now available $[21,22]$. Therefore, a new systematic review is needed. The objective of this study was to systematically evaluate the potential benefits of treatment approaches including cetuximab for patients with pancreatic cancer.

\section{Methods}

This systematic review and meta-analysis was conducted according to an a priori defined protocol (PROSPERO CRD42017064450) and is reported according to the PRISMA guidelines [23]. The resources and facilities of the University of Heidelberg were used to conduct this study. There was no additional source of funding.

\section{Systematic Literature Search}

The Cochrane CENTRAL, MEDLINE (via PubMed), and Web of Science databases were searched [24] throughout July 2018. A search strategy based on a thesaurus (MeSH or Emtree) in combination with free text words was used. The search strategy for MEDLINE (via PubMed) was as follows:

((cetuximab[tw] OR (Erbitux[tw] OR "cetuximab"[Mesh]) AND (pancrea*[tw] OR "Pancreas" [Mesh]))

In addition, reference lists of relevant studies and related systematic reviews were screened manually. References citing trials eligible for inclusion were searched using the Science Citation Index via Web of Science. No language restriction was applied.

\section{Study Selection}

Randomised controlled trials (RCTs) investigating any treatment concept including cetuximab for the treatment of any stage of pancreatic cancer in a human adult population and reporting at least one clinically relevant endpoint (i.e., overall survival, progression-free survival, or objective response) were eligible for inclusion.

Following the recommendations of the Cochrane Collaboration [25], two independent reviewers screened the titles, abstracts, and full texts.

\section{Data Extraction}

Data extraction was also independently performed by two reviewers for quality assurance purposes [26]. A third reviewer resolved any discrepancies found by the first two reviewers.

The following items were extracted: title, author, year of publication, journal, language, trial duration, trial design, number of treatment groups, total number of patients, evaluable patients, withdrawals, loss to follow-up, funding source, and trial registration or published protocol.

Relevant outcome variables included overall survival, defined as the time period between beginning of randomisation and death for any reason; progression-free survival, defined as the time between randomisation and radiological progress of disease according to the RECIST criteria; objective response, defined as at least partial radiological remission of disease according to the RECIST criteria; and toxicity, as individually reported by the trials.

\section{Critical Appraisal (Bias)}

The methodological quality was assessed by the Cochrane Collaboration's tool for assessing risk of bias [25]. The tool includes six standard domains of bias: selection bias (random sequence generation, allocation concealment), performance bias (blinding of participants and personnel), detection bias (outcome assessment), attrition bias (incomplete outcome data), reporting bias (selective reporting), and other bias. Each domain was judged to be at low, unclear, or high risk of bias according to the Cochrane Handbook for Systematic Reviews of Interventions [25]. Quantitative and qualitative results were merged and the quality of the evidence for each outcome was rated using the GRADE approach [27].

\section{Statistical Analysis}

Meta-analyses were performed with Review Manager (RevMan) version 5.3.5 (The Cochrane Collaboration, The Nordic Cochrane Centre, Copenhagen, Denmark).

To measure effects, hazard ratios (HR) with $95 \%$ confidence intervals (CI) were used for time-to-event outcomes (overall survival and progression-free survival), and odds ratios (OR) with 95\% CI were used for the binary outcome (objective response). If a publication reported no HR or its corresponding standard error but contained appropriate information (e.g., Kaplan-Meier curves), the HR and its standard error were calculated using the methods provided by Tierney et al. [28] and Parmar et al. [29]. HRs were combined using the inverse-variance method, and ORs using the Mantel-Haenszel method. A random effects model was applied because relevant heterogeneity between the effects of the studies was assumed. Statistical heterogeneity was assessed by the $I^{2}$ statistics [30]. Potential publication bias could not be evaluated due to the small number of included trials. For the same reason, no subgroup or sensitivity analyses were conducted. 
Fig. 1. PRISMA flow chart.

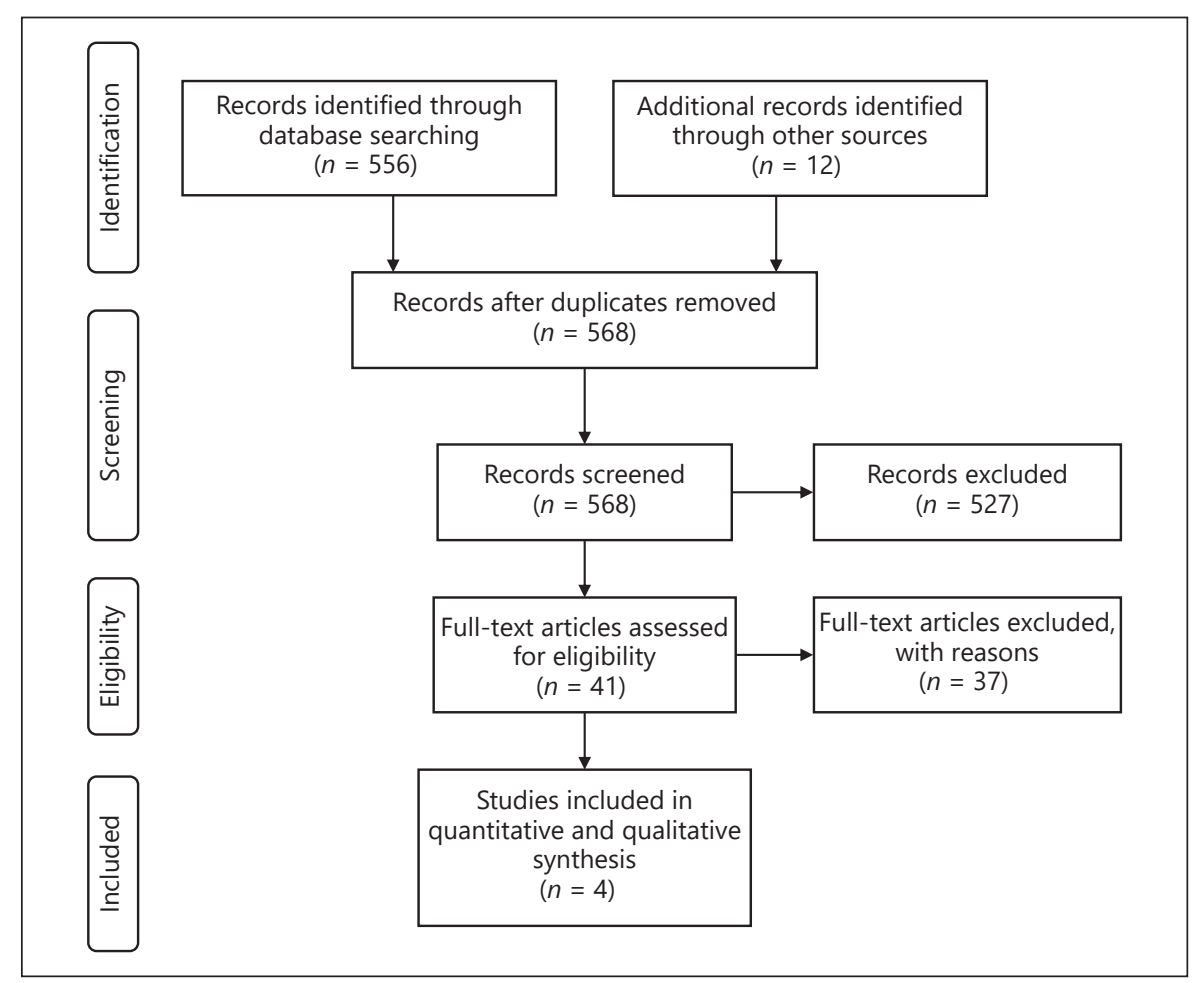

\section{Results}

A total of 568 articles were screened for eligibility. Of these, 41 were subject to full text analysis. Thirty-seven trials were excluded due to duplicate publication of the same cohort $(n=1)$, evaluation of a single treatment arm without a control group $(n=33)$, and a lack of information on clinical outcome $(n=3)$ (references available on request). Therefore, 4 RCTs with 924 patients were included in the qualitative and quantitative analysis $[10,21$, 22, 31]. A PRISMA flow chart is shown in Figure 1.

All RCTs evaluated cetuximab in a palliative setting. Regarding co-interventions, one trial investigated the combination of gemcitabine and cetuximab [10], one the combination of gemcitabine, cisplatin, and cetuximab [31], one the combination of gemcitabine, capecitabine, radiotherapy, and cetuximab [21], and one the combination of docetaxel, irinotecan, and cetuximab [22]. Two RCTs were conducted in Europe (Italy and the UK) [21, $31]$ and 2 originated from the USA [10, 22]. All RCTs had two trial arms with equally allocated treatment groups. The sample size varied across the trials (range: 13-743). The trials were published in journals with an impact factor of 3.25-13.28. An overview on the included RCTs is shown in Table 1.

Cetuximab in Pancreatic Cancer Therapy

\section{Critical Appraisal (Bias)}

Since all trials used an adequate measure of randomisation and allocation, none of them had a high risk of selection bias. Reporting of random sequence generation was precise (i.e., low risk of bias) in all 4 RCTs and for allocation concealment in 3 of the 4 RCTs. One RCT did not provide any information concerning this source of bias [21]. One trial was considered at a high risk of performance and detection bias, as neither participants nor personnel were blinded [10]. One trial reported appropriate blinding measures and was considered low risk [31]. Two trials did not report blinding measures and were at an unclear risk of bias [21,22]. All trials were at a low risk of attrition bias or reporting bias, and no other biases were present in the 4 RCTs. Overall, 3 of the 4 trials were at a low risk of bias in all reported domains [21, $22,31]$.

\section{Quantitative Analysis}

A quantitative analysis for overall survival, progression-free survival, and objective response was performed. Three of the 4 RCTs, with a total of 457 patients assigned to both the cetuximab and the non-cetuximab groups, reported overall survival rates. No significant difference in overall survival existed between the cetuximab and non- 
Table 1. List of included trials

\begin{tabular}{|c|c|c|c|c|c|c|c|c|c|c|c|c|c|}
\hline \multirow{2}{*}{$\begin{array}{l}\text { First } \\
\text { author/ } \\
\text { year }\end{array}$} & \multirow[t]{2}{*}{ Origin } & \multirow[t]{2}{*}{ Setting } & \multirow[t]{2}{*}{ Comparator } & \multicolumn{6}{|c|}{ Risk of bias } & \multirow{2}{*}{$\begin{array}{l}\text { Sample } \\
\text { size }\end{array}$} & \multicolumn{3}{|c|}{ Outcomes } \\
\hline & & & & $\mathrm{R}$ & A & B1 & B2 & IO & SR & & OS & PFS & ObR \\
\hline $\begin{array}{l}\text { Cascinu } \\
{[31], 2008}\end{array}$ & Italy & palliative & $\begin{array}{l}\text { gemcitabine/ } \\
\text { cisplatin }\end{array}$ & $\oplus$ & $\oplus$ & $\oplus$ & $\oplus$ & $\oplus$ & $\oplus$ & 81 & NC & $\mathrm{NC}$ & $\mathrm{C}$ \\
\hline $\begin{array}{l}\text { Philip } \\
{[10], 2010}\end{array}$ & USA & palliative & gemcitabine & $\bigoplus$ & $\oplus$ & $\ominus$ & $\oplus$ & $\oplus$ & $\oplus$ & 743 & $=$ & $=$ & $=$ \\
\hline $\begin{array}{l}\text { Khan } \\
{[21], 2016}\end{array}$ & UK & palliative & $\begin{array}{l}\text { gemcitabine/ } \\
\text { capecitabine + } \\
\text { RT }\end{array}$ & $\oplus$ & $?$ & $?$ & $?$ & $\bigoplus$ & $\bigoplus$ & 13 & $=$ & $\mathrm{C}$ & $\mathrm{C}$ \\
\hline $\begin{array}{l}\text { Burtness } \\
{[22], 2016}\end{array}$ & USA & palliative & $\begin{array}{l}\text { docetaxel/ } \\
\text { irinotecan }\end{array}$ & $\oplus$ & $\bigoplus$ & $?$ & $?$ & $\oplus$ & $\oplus$ & 87 & $\mathrm{NC}$ & $=$ & $\mathrm{C}$ \\
\hline
\end{tabular}

RT, radiotherapy; R, randomization sequence; A, allocation concealment; B1, blinding of participants; B2, blinding of outcome assessment; IO, incomplete outcome data; SR, selective reporting; $\bigoplus$, low risk of bias; $\ominus$, high risk of bias; ?, unclear risk of bias; OS, overall survival; PFS: progression-free survival; ObR, objective response; $\mathrm{C}$, favours cetuximab; $\mathrm{NC}$, favours non-cetuximab; =, no difference.

cetuximab groups (HR 1.04; 95\% CI: 0.90-1.19; $p=0.60$ ) (Fig. 2a).

In 3 of the 4 RCTs reporting on progression-free survival, 457 patients were treated with cetuximab (with 457 patients in the control group). Progression-free survival was not different between the groups (HR 1.06; 95\% CI: $0.93-1.22$; $p=0.36$ ) (Fig. 2b).

Objective response as defined by RECIST criteria was reported in all 4 RCTs, but in a smaller population of patients (cetuximab group: 418 patients, non-cetuximab group: 423 patients). Compared to the control group, patients treated with cetuximab had no significant benefit in objective response (OR 0.99; 95\% CI: 0.66-1.49; $p<$ 0.96) (Fig. 2c).

Altogether, cetuximab did not show any effect on the outcomes analysed. Statistical heterogeneity among the included trials could not be detected $\left(I^{2}=0 \%\right.$ for all outcomes). Due to inconsistent reporting of toxicity in the trials, a meta-analysis was not possible. Table 2 shows a summary of reported toxicity, which was the same or higher in the cetuximab group.

\section{Discussion}

The objective of this systematic review was to summarise, evaluate, and critically appraise evidence for the potential benefit of cetuximab in the treatment of pancreatic cancer. Cetuximab suggested promising results in preclinical studies when added to gemcitabine in the treatment of human pancreatic carcinoma xenografts $[17,18]$. In this systematic review, 4 RCTs adding cetuximab to standard palliative therapy were included. Cetuximab failed to demonstrate improved patient outcomes in terms of survival or objective response when compared to various chemotherapeutic regimens and/or other biological agents. According to the GRADE approach, the certainty of the evidence is high (Table 3). A quantitative analysis of toxicity was not possible; however, many severe side effects of cetuximab are known: reported grade 3 or 4 adverse events following the use of cetuximab include abdominal pain, neutropenia, thrombocytopenia, diarrhoea, nausea, allergy, and toxic skin reactions [32, 33]. Further, it is obvious that adding a drug to any standard care means higher costs. Therefore, in the presence of no survival benefit, the same or increased toxicity, and higher costs, a decreased cost-benefit ratio compared to the standard care must be suggested.

In the presence of existing synoptic evidence on this topic, it is important to compare those results with the present paper. Three systematic reviews investigating EGFR inhibitors in pancreatic cancer were found $[19,20$, 34]. These reviews were published in 2010 and 2013, evaluating only one or two RCTs and not including the newest ones on this topic. Consequently, the present study contains the most comprehensive sample of trials using cetuximab in the treatment of patients with pancreatic cancer. The review of Liu et al. [34] investigated cetuximab in all kinds of advanced cancer and found a general benefit regarding survival; however, not for advanced 
Table 2. Toxic effects reported in included trials

\begin{tabular}{|c|c|c|}
\hline $\begin{array}{l}\text { First author/ } \\
\text { year }\end{array}$ & Cetuximab & Non-cetuximab \\
\hline $\begin{array}{l}\text { Cascinu } \\
{[31], 2008}\end{array}$ & $\begin{array}{l}43 \% \text { of patients with grade III or IV toxic effect; } \\
\text { most frequently reported adverse effect was skin } \\
\text { toxicity }\end{array}$ & $36 \%$ of patients with grade III or IV toxic effects \\
\hline $\begin{array}{l}\text { Philip } \\
{[10], 2010}\end{array}$ & $\begin{array}{l}48 \% \text { grade II, } 8 \% \text { grade III, } 14 \% \text { grade IV, and } 2 \% \\
\text { of patients with grade V toxicity; } 1 \% \text { died during } \\
\text { treatment; increased frequency of allergic reaction } \\
\text { and skin toxicity }\end{array}$ & $\begin{array}{l}11 \% \text { of patients had grade IV or V toxic effects; } 0.3 \% \text { of } \\
\text { patients with grade V toxicity and } 0.3 \% \text { of patients died } \\
\text { during treatment }\end{array}$ \\
\hline $\begin{array}{l}\text { Khan } \\
{[21], 2016}\end{array}$ & Well tolerated without grade III or IV toxic effects & Well tolerated \\
\hline $\begin{array}{l}\text { Burtness } \\
{[22], 2016}\end{array}$ & $\begin{array}{l}56 \% \text { grade III and } 20 \% \text { grade IV toxicity; most } \\
\text { common toxic effect was diarrhoea; } 5 \% \text { of patients } \\
\text { with grade V toxicity reported (diarrhoea with } \\
\text { sepsis and neutropenia with fever) }\end{array}$ & $\begin{array}{l}57 \% \text { grade III and } 17 \% \text { grade IV toxicity; most common } \\
\text { toxic effects were nausea and diarrhoea; } 3 \% \text { of patients with } \\
\text { grade V toxicity reported (neutropenia with fever) }\end{array}$ \\
\hline
\end{tabular}

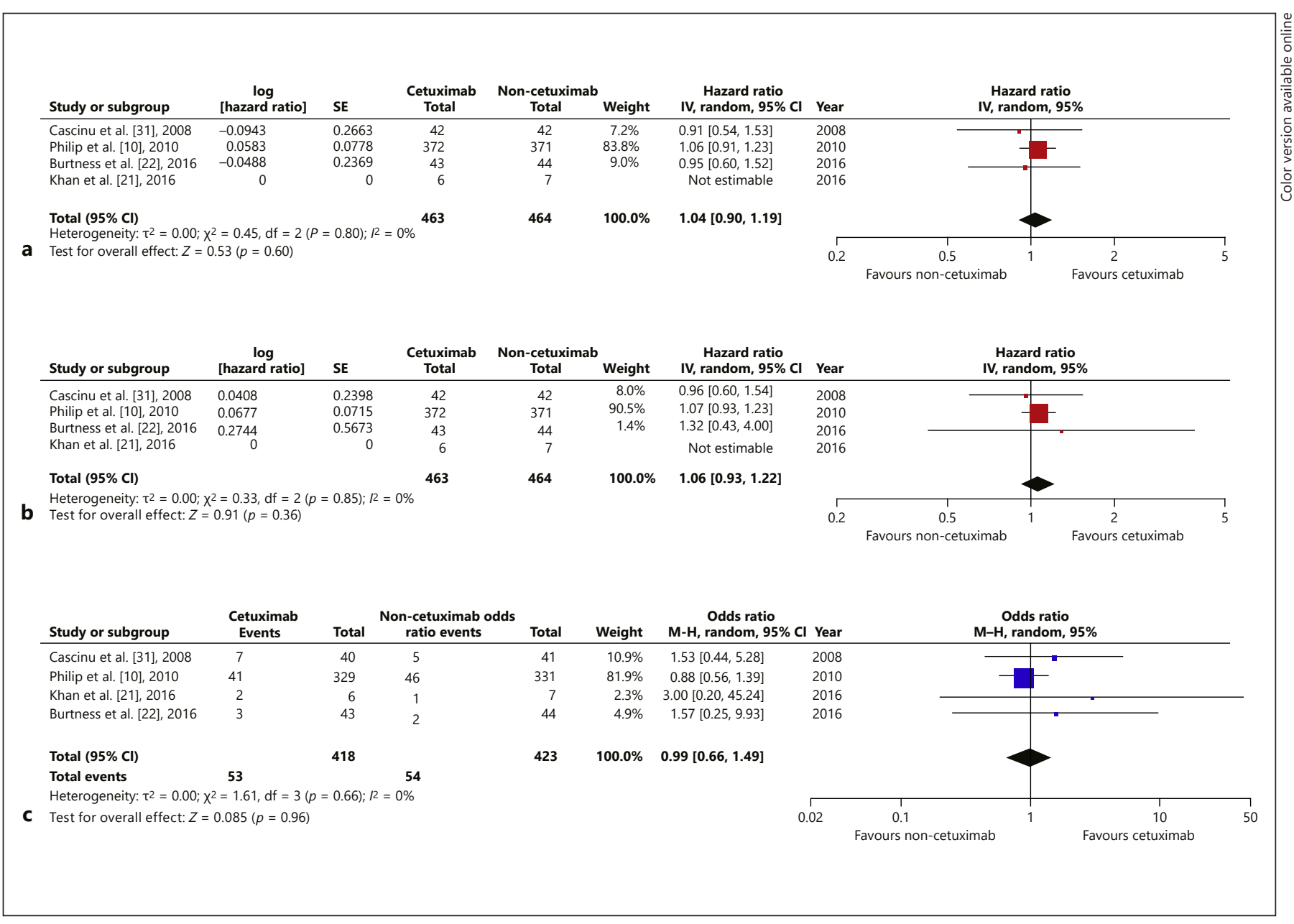

Fig. 2. Forest plots of overall survival (a), progression-free survival (b), and objective response (c). 
Table 3. Summary of findings with quality of evidence (GRADE)

\begin{tabular}{|c|c|c|c|}
\hline Outcomes & $\begin{array}{l}\text { Participants } \\
\text { (studies), } n\end{array}$ & $\begin{array}{l}\text { Certainty of the evidence } \\
\text { (GRADE) }\end{array}$ & $\begin{array}{l}\text { Relative effect } \\
\text { (95\% confidence interval) }\end{array}$ \\
\hline Overall survival & 914 (3 RCTs) & $\oplus \bigoplus \oplus \oplus \mathrm{HIGH}$ & HR 1.04 (0.90-1.19) \\
\hline Progression-free survival & 914 (3 RCTs) & $\bigoplus \oplus \oplus \oplus \mathrm{HIGH}$ & HR $1.06(0.93-1.22)$ \\
\hline Objective response & 841 (4 RCTs) & $\bigoplus \oplus \oplus \oplus \mathrm{HIGH}$ & OR 0.99 (0.66-1.49) \\
\hline
\end{tabular}

GRADE Working Group grades of evidence. High certainty: we are very confident that the true effect lies close to that of the estimate of the effect. Moderate certainty: we are moderately confident in the effect estimate; the true effect is likely to be close to the estimate of the effect, but there is a possibility that it is substantially different. Low certainty: our confidence in the effect estimate is limited; the true effect may be substantially different from the estimate of the effect. Very low certainty: we have very little confidence in the effect estimate; the true effect is likely to be substantially different from the estimate of effect.

pancreatic cancer. The review from Tian et al. [20], evaluating the use of EGFR inhibitors in the treatment of pancreatic cancer, shows no improvement in objective response and progression-free survival. The benefit of agents against EGFR on overall survival was shown, but this improvement in overall survival is likely because the authors did not specifically evaluate the effect of cetuximab alone, but also included other agents against EGFR, such as erlotinib. Similarly, Zagouri et al. [19] investigated different molecularly targeted therapies in metastatic pancreatic cancer and found the results promising to further investigate such therapies in pancreatic cancer disease.

Two limitations of the existing literature must be discussed: the heterogeneous control groups and the unselected patient population.

The standard of care in the included RCTs was highly varied. While Philip et al. [10] combined cetuximab with gemcitabine only, other RCTs used a combination of cetuximab with gemcitabine and cisplatin, or gemcitabine and capecitabine [21,31]. One RCT even involved radiotherapy [21], and one did not use gemcitabine at all, combining cetuximab with docetaxel and irinotecan [22]. As a result, the control group for the meta-analyses is clinically heterogeneous. However, adding cetuximab to any treatment regime did not result in clinical benefit.

One critical point regarding cetuximab trials in pancreatic cancer patients is the fact that all studies were performed in unselected patients. It is well established that cetuximab is not effective in colorectal cancer patients with KRAS or NRAS mutations but very effective in those with RAS wild-type mutations [35]. Since more than $90 \%$ of patients with pancreatic cancer harbour mutations in the KRAS gene [36], it is not surprising that cetuximab is ineffective against this disease. Indeed, a randomised phase II trial investigating the combination of nimotuzumab, a different anti-EGFR monoclonal antibody, with gemcitabine showed a significant advantage in 1-year overall survival of 53.8 versus $15.8 \%$ for the combination group in KRAS wild-type patients (HR $0.32, p=0.026$ ), while the difference in KRAS-mutated patients was not statistically significant [37]. Furthermore, KRAS mutations are not the only molecular changes in pancreatic cancer; although pancreatic cancer does not harbour the most genetic alterations of all solid tumours, those that exist are spread over all relevant pathways with mutations in every patient [38]. This is one explanation why the conventional targeted therapy approach is not effective [39], but profiling of all druggable targets and a subsequent holistic analysis is required [40].

In conclusion, further trials investigating cetuximab in an unselected pancreatic cancer population must be viewed with a critical eye. The upper bound of the pooled effect for overall survival excludes a clinically relevant effect. A future RCT would therefore be unlikely to change the effect estimate or could even be unethical in the light of the data presented here. Further research in pancreatic cancer should focus on other treatment regimens than those including cetuximab or should investigate the benefit of cetuximab in the small minority of KRAS wild-type patients, respecting the entirety of all mutations in this dire tumour.

\section{Significant Conclusions}

Adding cetuximab to pancreatic cancer therapy has no benefit. Conducting further RCTs in unselected patient populations is discouraged.
Forster et al. 


\section{Statement of Ethics}

Ethical approval was not required as the present work is a meta-analysis.

\section{Disclosure Statement}

The authors declare no competing interests according to the ICMJE guidelines that could have inappropriately influenced their work on this article.

\section{Funding Sources}

The resources and facilities of the University of Heidelberg were used in conducting this study. This research did not receive any specific grant from funding agencies in the public, commercial, or not-for-profit sectors.

\section{Author Contributions}

Tobias Forster: planning of the study, screening of publications, formal analysis, biometric and statistical analysis, original draft, and writing. Felix J. Hüttner, Christoph Springfeld, Matthias Löhr, Thilo Hackert, and Markus K. Diener: review and editing. Eva Kalkum: literature search. Matthes Hackbusch: Biometric and statistical analysis. Pascal Probst: planning of the study, screening of publications, formal analysis, biometric and statistical analysis, writing, review, and editing. All authors read and approved the final paper.

\section{Data Availability}

All data can be obtained from the corresponding author on reasonable request.

\section{References}

1 Löhr JM. Pancreatic cancer should be treated as a medical emergency. BMJ. 2014 Sep; 349:g5261.

2 Kleeff J, Korc M, Apte M, La Vecchia C, Johnson $\mathrm{CD}$, Biankin AV, et al. Pancreatic cancer. Nat Rev Dis Primers. 2016 Apr;2(1):16022.

3 Neoptolemos JP, Kleeff J, Michl P, Costello E, Greenhalf W, Palmer DH. Therapeutic developments in pancreatic cancer: current and future perspectives. Nat Rev Gastroenterol Hepatol. 2018 Jun;15(6):333-48.

4 Tempero M, Plunkett W, Ruiz Van Haperen V, Hainsworth J, Hochster H, Lenzi R, et al. Randomized phase II comparison of dose-intense gemcitabine: thirty-minute infusion and fixed dose rate infusion in patients with pancreatic adenocarcinoma. J Clin Oncol. 2003 Sep;21(18):3402-8.

5 Burris HA 3rd, Moore MJ, Andersen J, Green MR, Rothenberg ML, Modiano MR, et al. Improvements in survival and clinical benefit with gemcitabine as first-line therapy for patients with advanced pancreas cancer: a randomized trial. J Clin Oncol. 1997 Jun;15(6): 2403-13.

6 Conroy T, Desseigne F, Ychou M, Bouché O, Guimbaud R, Bécouarn Y, et al.; Groupe Tumeurs Digestives of Unicancer; PRODIGE Intergroup. FOLFIRINOX versus gemcitabine for metastatic pancreatic cancer. N Engl J Med. 2011 May;364(19):1817-25.

7 Mosquera C, Maglic D, Zervos EE. Molecular targeted therapy for pancreatic adenocarcinoma: A review of completed and ongoing late phase clinical trials. Cancer Genet. 2016 Dec;209(12):567-81.
8 Moore MJ, Goldstein D, Hamm J, Figer A, Hecht JR, Gallinger S, et al.; National Cancer Institute of Canada Clinical Trials Group. Erlotinib plus gemcitabine compared with gemcitabine alone in patients with advanced pancreatic cancer: a phase III trial of the National Cancer Institute of Canada Clinical Trials Group. J Clin Oncol. 2007 May;25(15):19606.

9 Lima CS, Lin EH, Kim GP, et al. Phase II trial of ixabepilone (IXA) plus cetuximab (C) as first-line therapy for advanced pancreatic carcinoma (PC). J Clin Oncol. 2010 May;28(suppl 15):4086.

10 Philip PA, Benedetti J, Corless CL, Wong R, O’Reilly EM, Flynn PJ, et al. Phase III study comparing gemcitabine plus cetuximab versus gemcitabine in patients with advanced pancreatic adenocarcinoma: southwest Oncology Group-directed intergroup trial S0205. J Clin Oncol. 2010 Aug;28(22):3605-10.

11 Rembielak A, Saleem A, Valle J, et al. Phase II study of cetuximab and radiotherapy in patients with locally advanced pancreatic cancer (PACER Study). Clin Oncol. 2009 Apr;21(3): 254-5.

12 Rembielak AI, Jain P, Jackson AS, Green MM, Santorelli GR, Whitfield GA, et al. Phase II Trial of Cetuximab and Conformal Radiotherapy Only in Locally Advanced Pancreatic Cancer with Concurrent Tissue Sampling Feasibility Study. Transl Oncol. 2014 Feb; 7(1):55-64.

13 Merchan JR, Ferrell A, Macintyre J, Ciombor KK, Levi J, Ribeiro A, et al. Phase II study of gemcitabine, oxaliplatin, and cetuximab in advanced pancreatic cancer. Am J Clin Oncol. 2012 Oct;35(5):446-50.
14 Mendelsohn J. Targeting the epidermal growth factor receptor for cancer therapy. Clin Oncol. 2002 Sep;20(18 Suppl):1S-13S.

15 Korc M, Chandrasekar B, Yamanaka Y, Friess $\mathrm{H}$, Buchier M, Beger HG. Overexpression of the epidermal growth factor receptor in human pancreatic cancer is associated with concomitant increases in the levels of epidermal growth factor and transforming growth factor alpha. J Clin Invest. 1992 Oct;90(4):1352-60.

16 Friess H, Wang L, Zhu Z, Gerber R, Schröder M, Fukuda A, et al. Growth factor receptors are differentially expressed in cancers of the papilla of vater and pancreas. Ann Surg. 1999 Dec;230(6):767-74; discussion 774-5.

17 Tai CJ, Wang H, Wang CK, Tai CJ, Huang $\mathrm{MT}, \mathrm{Wu} \mathrm{CH}$, et al. Bevacizumab and cetuximab with conventional chemotherapy reduced pancreatic tumor weight in mouse pancreatic cancer xenografts. Clin Exp Med. 2017 May;17(2):141-50.

18 Larbouret C, Robert B, Bascoul-Mollevi C, Penault-Llorca F, Ho-Pun-Cheung A, Morisseau $S$, et al. Combined cetuximab and trastuzumab are superior to gemcitabine in the treatment of human pancreatic carcinoma xenografts. Ann Oncol. 2010 Jan;21(1):98-103.

19 Zagouri F, Sergentanis TN, Chrysikos D, Zografos CG, Papadimitriou CA, Dimopoulos MA, et al. Molecularly targeted therapies in metastatic pancreatic cancer: a systematic review. Pancreas. 2013 Jul;42(5):760-73. 
20 Tian W, Ding W, Kim S, Xu X, Pan M, Chen S. Efficacy and safety profile of combining agents against epidermal growth factor receptor or vascular endothelium growth factor receptor with gemcitabine-based chemotherapy in patients with advanced pancreatic cancer: a meta-analysis. Pancreatology. 2013 Jul-Aug;13(4):415-22.

21 Khan K, Cunningham D, Peckitt C, Barton S, Tait D, Hawkins M, et al. miR-21 expression and clinical outcome in locally advanced pancreatic cancer: exploratory analysis of the pancreatic cancer Erbitux, radiotherapy and UFT (PERU) trial. Oncotarget. 2016 Mar; 7(11):12672-81.

22 Burtness B, Powell M, Catalano P, Berlin J, Liles DK, Chapman AE, et al. Randomized Phase II Trial of Irinotecan/Docetaxel or Irinotecan/Docetaxel Plus Cetuximab for Metastatic Pancreatic Cancer: An Eastern Cooperative Oncology Group Study. Am J Clin Oncol. 2016 Aug;39(4):340-5.

23 Moher D, Liberati A, Tetzlaff J, Altman DG; PRISMA Group. Preferred reporting items for systematic reviews and meta-analyses: the PRISMA statement. Int J Surg. 2010;8(5): 336-41.

24 Goossen K, Tenckhoff S, Probst P, Grummich K, Mihaljevic AL, Büchler MW, et al. Optimal literature search for systematic reviews in surgery. Langenbecks Arch Surg. 2018 Feb; 403(1):119-29.

25 Higgins JPT, Green S, editors. Cochrane Handbook for Systematic Reviews of Interventions, Version 5.1.0 [updated March 2011]. The Cochrane Collaboration. Available from: https://handbook-5-1.cochrane. org/.

26 Buscemi N, Hartling L, Vandermeer B, Tjosvold L, Klassen TP. Single data extraction generated more errors than double data extraction in systematic reviews. J Clin Epidemiol. 2006 Jul;59(7):697-703.
27 Guyatt GH, Oxman AD, Vist GE, Kunz R, Falck-Ytter Y, Alonso-Coello P, et al.; GRADE Working Group. GRADE: an emerging consensus on rating quality of evidence and strength of recommendations. BMJ. 2008 Apr;336(7650):924-6.

28 Tierney JF, Stewart LA, Ghersi D, Burdett S, Sydes MR. Practical methods for incorporating summary time-to-event data into metaanalysis. Trials. 2007 Jun;8(1):16.

29 Parmar MK, Torri V, Stewart L. Extracting summary statistics to perform meta-analyses of the published literature for survival endpoints. Stat Med. 1998 Dec;17(24):2815-34.

30 Higgins JP, Thompson SG, Deeks JJ, Altman DG. Measuring inconsistency in meta-analyses. BMJ. 2003 Sep;327(7414):557-60.

31 Cascinu S, Berardi R, Labianca R, Siena S, Falcone A, Aitini E, et al.; Italian Group for the Study of Digestive Tract Cancer (GISCAD). Cetuximab plus gemcitabine and cisplatin compared with gemcitabine and cisplatin alone in patients with advanced pancreatic cancer: a randomised, multicentre, phase II trial. Lancet Oncol. 2008 Jan;9(1):39-44.

32 Kullmann F, Hollerbach S, Dollinger MM, Harder J, Fuchs M, Messmann H, et al. Cetuximab plus gemcitabine/oxaliplatin (GEMOXCET) in first-line metastatic pancreatic cancer: a multicentre phase II study. Br J Cancer. 2009 Apr;100(7):1032-6.

33 Xiong HQ, Rosenberg A, LoBuglio A, Schmidt W, Wolff RA, Deutsch J, et al. Cetuximab, a monoclonal antibody targeting the epidermal growth factor receptor, in combination with gemcitabine for advanced pancreatic cancer: a multicenter phase II Trial. J Clin Oncol. $2004 \mathrm{Jul} ; 22(13): 2610-6$.
34 Liu L, Cao Y, Tan A, Liao C, Gao F. Cetuximab-based therapy versus non-cetuximab therapy for advanced cancer: a meta-analysis of 17 randomized controlled trials. Cancer Chemother Pharmacol. 2010 Apr;65(5):84961.

35 Sorich MJ, Wiese MD, Rowland A, Kichenadasse G, McKinnon RA, Karapetis CS. Extended RAS mutations and anti-EGFR monoclonal antibody survival benefit in metastatic colorectal cancer: a meta-analysis of randomized, controlled trials. Ann Oncol. 2015 Jan; 26(1):13-21.

36 Dreyer SB, Chang DK, Bailey P, Biankin AV. Pancreatic Cancer Genomes: Implications for Clinical Management and Therapeutic Development. Clin Cancer Res. 2017 Apr;23(7): 1638-46.

37 Schultheis B, Reuter D, Ebert MP, Siveke J, Kerkhoff A, Berdel WE, et al. Gemcitabine combined with the monoclonal antibody nimotuzumab is an active first-line regimen in KRAS wildtype patients with locally advanced or metastatic pancreatic cancer: a multicenter, randomized phase IIb study. Ann Oncol. 2017 Oct;28(10):2429-35.

38 Jones S, Zhang X, Parsons DW, Lin JC, Leary RJ, Angenendt $P$, et al. Core signaling pathways in human pancreatic cancers revealed by global genomic analyses. Science. 2008 Sep; 321(5897):1801-6.

39 Löhr JM, Kordes M, Rutkowski W, et al. Overcoming diagnostic issues in precision treatment of pancreatic cancer. Exp Rev Prec Med Drug Devel. 2018;3:189-95.

40 Malgerud L, Lindberg J, Wirta V, GustafssonLiljefors M, Karimi M, Moro CF, et al. Bioinformatory-assisted analysis of next-generation sequencing data for precision medicine in pancreatic cancer. Mol Oncol. 2017 Oct; 11(10):1413-29. 